University of Nebraska - Lincoln

DigitalCommons@University of Nebraska - Lincoln

Roman L. Hruska U.S. Meat Animal Research

U.S. Department of Agriculture: Agricultural Center

Research Service, Lincoln, Nebraska

$1-16-2021$

\title{
iTRAQ-based proteomic analysis of bovine pre-ovulatory plasma and follicular fluid
}

\author{
P A. Afedi \\ South Dakota State University \\ E L. Larimore \\ South Dakota State University \\ R A. Cushman \\ U.S. Meat Animal Research Center, Clay Center \\ D Raynie \\ South Dakota State University \\ G A. Perry \\ South Dakota State University, George.Perry@ag.tamu.edu
}

Follow this and additional works at: https://digitalcommons.unl.edu/hruskareports

Afedi, P A.; Larimore, E L.; Cushman, R A.; Raynie, D; and Perry, G A., "iTRAQ-based proteomic analysis of bovine pre-ovulatory plasma and follicular fluid" (2021). Roman L. Hruska U.S. Meat Animal Research Center. 476.

https://digitalcommons.unl.edu/hruskareports/476

This Article is brought to you for free and open access by the U.S. Department of Agriculture: Agricultural Research Service, Lincoln, Nebraska at DigitalCommons@University of Nebraska - Lincoln. It has been accepted for inclusion in Roman L. Hruska U.S. Meat Animal Research Center by an authorized administrator of DigitalCommons@University of Nebraska - Lincoln. 


\title{
iTRAQ-based proteomic analysis of bovine pre-ovulatory plasma and follicular fluid
}

\author{
P.A. Afedi ${ }^{\text {a }}$, E.L. Larimore ${ }^{b}$, R.A. Cushman ${ }^{\text {, }}$ D. Raynie ${ }^{a}$, G.A. Perry ${ }^{\text {b,* }}$ \\ ${ }^{a}$ Department of Chemistry and Biochemistry, South Dakota State University, Brookings, SD, USA \\ ${ }^{\mathrm{b}}$ Department of Animal Science, South Dakota State University, Brookings, SD, USA \\ ' USDA-ARS, U.S. Meat Animal Research Center, Clay Center, NE 68933, USA
}

\section{A R T I C L E I N F O}

\section{Article history:}

Received 28 September 2020

Received in revised form 5 January 2021

Accepted 16 January 2021

\section{Keywords:}

Estradiol

Proteomics

Follicular fluid

Plasma

Reproductive associated protein

\begin{abstract}
A B S T R A C T
Bovine follicular fluid (FF) creates a unique microenvironment in follicles necessary for follicle growth, oocyte maturation, and estradiol (E2) production. The objective of this study was to analyze changes in proteins in FF and plasma (PL) from animals with high E2 (HE2) or low E2 (LE2) during the preovulatory period. Beef cows were synchronized, and follicular dynamics and ovulatory response were monitored using transrectal ultrasonography. Nine cows were selected and slaughtered, blood samples were collected at slaughter and FF was aspirated from dominant follicles (DF; $>10 \mathrm{~mm}$ ). Abundant proteins (albumin, IgG, IgA, and alpha-1-antitrypsin) were depleted from both PL and FF. Peptides were labeled with iTRAQ reagents and quantified using 2-dimentional liquid chromatography ESI-based mass spectrometry. Estradiol was associated with protein changes in PL and FF. Protein expression changes between FF HE2 and FF LE2 were greater than between PL HE2 and PL LE2. There were 15 up-regulated proteins and 10 down-regulated proteins in FF HE2 compared to FF LE2, and 7 proteins up-regulated and 9 proteins down-regulated in PL HE2 compared to PL LE2. Several of the differentially expressed proteins function in follicle development and were mainly categorized under cellular process and metabolic process. Pathway analysis identified the up- and down-regulated proteins were predominantly associated with the complement and coagulation cascades. The data demonstrate E2 regulates a wide range of reproductive associated proteins in bovine PL and FF and can provide the basis for further investigation of specific processes involved in such regulation.
\end{abstract}

(c) 2021 Elsevier Inc. All rights reserved.

\footnotetext{
* Names are necessary to report factually on available data; however, neither South Dakota State University nor the USDA neither guarantees nor warrants the standard of the product, and use of names by South Dakota State University or the USDA implies no approval of the product to the exclusion of others that may also be suitable.

fur The U.S. Department of Agriculture (USDA) prohibits discrimination in all its programs and activities on the basis of race, color, national origin, age, disability, and where applicable, sex, marital status, familial status, parental status, religion, sexual orientation, genetic information, political beliefs, reprisal, or because all or part of an individual's income is derived from any public assistance program. (Not all prohibited bases apply to all programs.) Persons with disabilities who require alternative means for communication of program information (Braille, large print, audiotape, etc.) should contact USDA's TARGET Center at (202) 720-2600 (voice and TDD). To file a complaint of discrimination, write to USDA, Director, Office of Civil Rights, 1400 Independence Avenue, S.W., Washington, D.C. 20250-9410, or call (800) 795-3272 (voice) or (202) 720-6382 (TDD). USDA is an equal opportunity provider and employer.

* Corresponding author. Texas A\&M AgriLife Research and Extension Center, 1710 FM 3053 N, Overton, TX 75684. Tel.: +1 9038346191 ; fax: +1 9038347141 .

E-mail address: George.Perry@ag.tamu.edu (G.A. Perry).
} 


\section{Introduction}

Follicular fluid (FF) provides a unique microenvironment for developing oocytes. It contains substances that primarily originate from circulating blood and from secretions by granulosa cells (GCs), theca cells and the oocyte [1]. Proteins are a major proportion of the FF with total concentration comparable with that in plasma [2]; however, the composition of the proteins in FF changes with follicle development $[3,4]$ which indicates their involvement in the development of the follicle and competence of the oocyte. Accordingly, FF proteins have been implicated in oocyte meiosis, ovulation, formation of the corpus luteum and fertilization [1]. Thus, FF proteins can reflect the physiological condition of the follicle and may serve as biomarkers for follicle growth and maturation. Blood plasma proteins are also important indicator of folliculogenesis and ovulation because of the significant amount of proteins able to cross the blood-follicular barrier during folliculogenesis.

Estrogens are an important component of FF. During the steroidogenesis, androgens produced in the theca cells traverse the basement membrane of the neighboring GCs where they are converted by cytochrome P450 aromatase (CYP19A1) under the influence of follicle stimulating hormone (FSH) to estrogens [5], with Estradiol-17 $\beta$ (E2) being the principal form of estrogen present $[5,6]$. The preovulatory follicle is reported to have the highest intra-follicular levels of E2 mainly because of the large number of GCs and its capacity for androgen aromatization [5].

In developing follicles, E2 stimulates proliferation and differentiation of GCs [5], and promotes growth, gapjunction formation, antrum formation and inhibition of atresia [7]. Perry et al. [8] reported that, among cows exhibiting standing estrus, peak concentration of E2 were greater and positively associated with follicle size, but this association was not found in cows not exhibiting standing estrus. Cows with increased concentration of circulating E2 had an up-regulation of the steroidogenic pathway during the preovulatory period as evidenced by increased concentrations of steroidogenic associated enzymes $3 \beta$-hydroxysteroid dehydrogenase ( $3 \beta$-HSD), CYP19A1, cytochrome P450 side-chain cleavage enzyme (CYP11A1), and steroidogenic products estradiol and androstenedione [9]. An important means by which E2 achieves its regulatory reproductive functions is via regulation of proteins and protein receptors involved in their relevant functions. Quantitative shot-gun proteomics, incorporating isobaric labeling techniques such as isobaric tags for relative and absolute quantitation (iTRAQ) and tandem mass tags (TMT), allow measuring of protein changes with greater precision and accuracy than label-free methods [10]. Thus this method can be applied to determine changes in the expression of several proteins in a short period. Its application to $\mathrm{FF}$ is beneficial considering the large number and diversity of the FF proteome. Ferrazza et al. [3] recently utilized TMT labels and identified 22 differentially expressed proteins in bovine FF between different stages of follicle development. The group also demonstrated a correlation between some of the differentially expressed proteins (modified fibrinogen, alpha-2-macroglobulin, plas- minogen, immunoglobulin $\mathrm{M}$ heavy chain, and spondin-1) and concentration of E2 or progesterone. The objective of this study was to use the iTRAQ proteomic approach to quantitatively measure changes in PL and FF proteomes between animals with high or low preovulatory circulating concentrations of E2. We specifically hypothesized that proteins involved in the final stages of folliculogenesis and the ovulatory process would be present in greater abundance in the FF of animals with increased circulating concentrations of E2.

\section{Materials and methods}

\subsection{Animals' experimental design}

All procedures were approved by the South Dakota State University Institutional Animal Care and Use Committee. Samples in the present study were collected from a previous study to characterize changes in steroidogenic enzymes and FF steroid concentrations [9]. Briefly, 32 cycling nonlactating beef cows (age $=4-10$ yrs; mean BCS of $5.5)$ were synchronized by an injection of $\mathrm{GnRH}$ (100 mg as $2 \mathrm{~mL}$ of Factrel, intramuscularly; Zoetis on day-7 and prostaglandin $\mathrm{F}_{2 \alpha}\left(\mathrm{PGF}_{2 \alpha}\right) 25 \mathrm{mg}$ as $5 \mathrm{~mL}$ of Lutalyse intramuscularly (Zoetis, Florham Park, NJ, USA) on day 0. Estrus was monitored every $3 \mathrm{~h}$ from PG on day 0 until hour 33 and at slaughter (hour 36-42) with the aid of EstroTect (Western Point, Inc, Apple Valley, MN, USA) estrus detection aids. Ovaries of all cows were examined on day-7, -4 , and 0 by transrectal ultrasonography using an Aloka 500V ultrasound with a $7.5-\mathrm{MHz}$ linear probe (Aloka, Wallingford, CT, USA) to assess follicular dynamics and ovulatory response. Ten cows that were determined to initiate a new follicular wave by day-4 (as determined by a cohort of growing follicle all less than $9 \mathrm{~mm}$ ) were slaughtered by captive bolt and exsanguination on day 2 (hour 36-42) for ovary collection. All cows had a CL present and a new follicular wave that had been initiated between days-7 and -4 . This would mean all follicles were growing in the presence of progesterone and would be at a similar stage of growth. However, ovaries were collected from 9 out of the 10 cows as one was determined to have a follicular cyst at time of slaughter and was excluded. Thus, a total of 9 cows were used for further study and data analysis. Estradiol (E2) concentrations in PL and FF were measured by radioimmunoassays (RIA) according to procedures as previously described [11]. Animals were classified based on circulating E2 concentrations in PL at 36 hrs after $\mathrm{PGF}_{2 \alpha}$ as either high E2 (peak PL estradiol $9.07 \pm 0.89 \mathrm{pg} / \mathrm{mL}$; PL: $n=4$, FF concentrations were $1,565 \pm 196.0 \mathrm{ng} / \mathrm{mL}$ ) or low E2 (peak PL estradiol $3.22 \pm 0.79 \mathrm{pg} / \mathrm{mL}$; PL: $n=5$, FF concentrations were $398 \pm 175.0 \mathrm{ng} / \mathrm{mL}$ ). Animals were classified into high and low E2 classification according to Jinks et al. [12] (Peak estradiol $>8.4 \mathrm{pg} \mathrm{mL}$ at $48 \mathrm{hrs}$ after $\mathrm{PGF}_{2 \alpha}$ ). Concentrations of E2 and changes in the steroidogenic pathway have previously been reported by Larimore and coworkers [9].

\subsection{Follicular fluid (FF) and blood samples collection}

All animals were harvested in the South Dakota State University Meat Laboratory. Within minutes of slaughter 
the reproductive tract was collected. Follicular fluid (FF) was aspirated from dominant follicles (DF; $>10 \mathrm{~mm}$ in diameter) and the GCs were separated from the FF by centrifugation (1,000 x g for $1 \mathrm{~min})$. The FF was place in RNase Free Tubes (USA Scientific), snap frozen in liquid nitrogen and stored at $-80^{\circ} \mathrm{C}$ until ready for analysis. Blood samples were collected at exsanguination to provide better comparison to the FF collected at slaughter. To obtain plasma, blood collected at slaughter was placed in EDTA vacutainer tubes (Beckman Dickerson) and centrifuged at 1,200 x g for $30 \mathrm{~min}$ at $4^{\circ} \mathrm{C}$. The plasma supernatant was snap frozen in liquid nitrogen and stored at $-80^{\circ} \mathrm{C}$ until ready for proteomic analysis.

\subsection{Depletion and Coomassie Bradford assay quantitation}

Depletion of the different bovine fluids (PL HE2, PL LE2, FF HE2, and FF LE2) were performed using the High Capacity Multiple Affinity Spin Cartridge (MARS Hu-6HC) \# 5188-5341 (Agilent Technologies, CA, USA) as previously reported [13]. Protein content in depleted samples was quantified using Coomassie (Bradford) assay kit (Pierce Biotechnology, IL, USA) according to manufacturer's instruction. Bovine serum albumin (Thermo Scientific, IL, USA) was used as a standard for making a calibration curve. Standard ( $2 \mathrm{mg} / \mathrm{mL}$ ) was diluted with $50 \mathrm{mM}$ TEAB and the calibration curve covered a concentration range of 0.00 to $1500 \mu \mathrm{g} / \mathrm{mL}$.

\subsection{Reduction, alkylation, digestion, and iTRAQ labeling of proteins}

Fifty micrograms of each of 4 depleted bovine samples (PL LE2, PL HE2, FF LE2, and FF HE2) containing high or low E2 were pooled and vacuum dried (Labconco, Kansas, $\mathrm{MO}$, USA) at $4^{\circ} \mathrm{C}$. The dried proteins were prepared with iTRAQ reagents according to manufacturer protocol (Applied Biosystems, Foster City, CA, USA). Briefly, the dried proteins were resuspended in $25 \mu \mathrm{L} 1 \mathrm{M}$ TEAB solution. The proteins were denatured with $1 \mu \mathrm{L} 2 \%$ SDS solution, reduced with $2 \mu \mathrm{L} 50 \mathrm{mM}$ tris-(2-carboxy) ethylphosphine hydrochloride (TCEP), and alkylated with1 $\mu \mathrm{L}$ of freshly prepared $84 \mathrm{mM}$ iodoacetamide solution and incubated in dark room temperature for $30 \mathrm{~min}$. Each sample $(50 \mu \mathrm{g})$ was digested overnight at $37^{\circ} \mathrm{C}$ with $10 \mu \mathrm{L}$ of freshly prepared $1 \mu \mathrm{g} / \mu \mathrm{L}$ TPCK treated trypsin solution, P/N 4370282 (Ab Sciex Pte Ltd, MA, USA). iTRAQ reagents 114, 115, 116, and 117 were each resuspended in $70 \mu \mathrm{L}$ ethanol and added individually to the 4 digested $\mathrm{PL}$ and FF protein samples. The samples were incubated at room temperature for $1 \mathrm{~h}$ and the reaction quenched by adding $100 \mu \mathrm{L}$ of HPLC grade water and incubating at room temperature for $30 \mathrm{~min}$. The iTRAQ-labeled peptides were vacuum dried at $4^{\circ} \mathrm{C}$, cleaned with Zeba desalting spin columns according to vendor instructions (Pierce, Rockford, IL, USA) and then vacuum dried at $4{ }^{\circ} \mathrm{C}$. Samples were stored at $-80^{\circ} \mathrm{C}$ until ready for analysis.

\subsection{Off-line strong cation exchange (SCX) separation}

The iTRAQ-labeled peptides were separated using Cation Exchange Cartridge, \# 4326695, Opti-Lynx Quick Connect Hardware, \# 4326688, and Cation Exchange Buffer Pack, \# 4326747 (Applied Biosystems, Foster City, CA, USA USA). The iTRAQ-labeled dried peptides were each diluted 10 -fold with Load Buffer ( $10 \mathrm{mM} \mathrm{KH}_{2} \mathrm{PO}_{4}$ in 25\% ACN; pH 3 ) and the 4 samples combined in one new vial. Equilibration of the SCX cartridge was done with $1 \mathrm{~mL}$ of Clean Buffer ( $10 \mathrm{mM} \mathrm{KH}_{2} \mathrm{PO}_{4}$ in $25 \% \mathrm{ACN} / 1 \mathrm{M} \mathrm{KCl}$; $\mathrm{pH} 3$ ) followed by 2-mL Load Buffer. The mixed iTRAQ labeled peptides were then loaded onto the SCX cartridge. Excess iTRAQ reagents and salts in the cartridge were removed by washing the cartridge with $1 \mathrm{~mL}$ of Load Buffer. The bound peptides on the cartridge were eluted by sequential injection of $500 \mu \mathrm{L}$ of a series of salt solutions: $0,30,40,50,60$, $70,85,100,130,160,350,500$, and $1,000 \mathrm{mM} \mathrm{KCl}$ in Load Buffer. The flow rate of elution was $\sim 1$ drop/s. Each eluted fraction and wash solution was cleaned with Zeba desalting spin columns according to vendor instructions (Pierce, Rockford, IL, USA). Purified peptides were vacuum dried at $4^{\circ} \mathrm{C}$ (Labconco, Kansas, MO, USA) and stored at $-80^{\circ} \mathrm{C}$ until further analysis.

\subsection{Nano-LC-MS/MS analysis}

Aliquots of the dried SCX peptide fractions were analyzed using the Thermo-Fisher Finnigan LTQ mass spectrometer equipped with a nano electrospray source (New Objective, Woburn, MA, USA) and coupled with a nano-LC separation system (Eksigent nanoLC 1D-plus). The LC system is equipped with an autosampler (Spark Holland 920 Endurance Autosampler). Each peptide fraction was resuspended in $10 \mu \mathrm{L}$ of water/ACN/formic acid (95\%/5\%/0.1\%) and then $3 \mu \mathrm{L}$ loaded onto IntegraFrit Sample trap, ProteoPep II C18, $300 \AA, 5 \mu \mathrm{m}, 100 \mu \mathrm{m} \times 25 \mathrm{~mm}$ (New Objective, Inc., Woburn, MA). The retained peptides were washed isocratically with water premixed with $0.1 \%$ formic acid pumped from channel $1 \mathrm{~A}$ to remove any excess reagents. Peptide separation was performed on an IntegraFrit Analytical Column (ProteoPep II C18, $75 \mu \mathrm{m} \times 100$ $\mathrm{mm}$, New Objective, Inc., Woburn, MA) with a multistep 4-h gradient using solvent A (water premixed with $0.1 \%$ formic acid) and solvent B (acetonitrile premixed with $0.1 \%$ formic acid) at a flow rate of $200 \mathrm{~nL} / \mathrm{min}$. The gradient started at 5\% solvent B and was held for $5 \mathrm{~min}$, then linearly increased to $50 \%$ solvent B at $205 \mathrm{~min}$ and to $95 \%$ solvent B at $213 \mathrm{~min}$ and finally held at $95 \%$ solvent B for 5 min before allowing to return to initial $5 \%$ solvent $B$ at 223 min. Column reequilibration with initial 5\% solvent B was done for $17 \mathrm{~min}$.

The LTQ mass spectrometer was operated in a datadependent mode. The full MS spectra were acquired in positive mode within a range of 400 to $1,800 \mathrm{~m} / \mathrm{z}$. The top 4 most intense ions in the acquired full mass scan were selected for followed pulsed Q dissociation (PQD) in LTQ. The $\mathrm{Q}$ activation and time was set respectively at $0.7 \mathrm{eV}$ and $0.1 \mathrm{~ms}$. The maximum ion injection times used were $50 \mathrm{~ms}$ for the MS scan and $120 \mathrm{~ms}$ for the MS/MS scans. One microscan of full MS was performed. The automatic 
gain control target settings were $3.0 \times 10^{4}$ for the MS scan mode and $1.0 \times 10^{4}$ for the MS/MS scan mode. The normalized collision energy was $29.5 \%$ and the isolation window employed was $2 \mathrm{~m} / \mathrm{z}$. The dynamic exclusion settings utilized were repeat count 2 , exclusion duration $25 \mathrm{~s}$, exclusion list size 500, exclusion mass width low 0.5 and exclusion mass width high 1.5 .

\subsection{Protein identification and quantification}

The LC-MS/MS raw data from nanoLC-LTQ were correlated to theoretical fragmentation patterns of tryptic peptide sequences in bovine protein fasta database using SEQUEST search engine embedded in Proteome Discoverer (version 2.1; Thermo Fisher Scientific). The search parameters included were as follows: fixed cysteine modifications of +57 Da for carbamidomethyl-cysteines, +144 Da for lysine-iTRAQ labeling and $\mathrm{N}$-terminal peptides; dynamic modifications allowing +16 with methionines for methionine sulfoxide and +144 Da for Y-iTRAQ labeling; restricted to trypsin digested peptides and allowed for 2 missed cleavages; precursor mass range was 350 to 5,000 Da; peptide mass tolerance of $2.5 \mathrm{Da}$ and fragment mass tolerance of $\pm 0.8 \mathrm{Da}$; target false discovery rate (FDR) strict was 0.01 and FDR relaxed was 0.05 ; most confident centroid was selected for peak integration method and a $0.25 \mathrm{Da}$ integration window tolerance was allowed. The proteins matched with at least one unique peptide at minimum $95 \%$ confidence were considered positive identifications. The FDR is a statistical measure of the certainty of the identifications and is calculated using $F$ values. The $F$-value calculation factors the primary score from the spectra library search (Dot Score) and the Dot Bias Score which is an indication of the number of spectra used in determining the Dot Score.

The relative quantification of proteins in the samples was performed with the Proteome Discover (1.2). The quantification utilized the relative peak intensities of the ITRAQ reporter ions derived from MS/MS spectra of all unique peptides that represented each protein. iTRAQ ratios of the reporter ions were calculated using reporter ions representing any 2 samples. The final ratios obtained from the relative protein quantifications were normalized according to the median protein quantification ratio. The protein ratios were the median ratio of the corresponding peptide ratios. To determine protein expression levels, a fold change of $>2.0$ or $<0.5$ between any pair from the 4 sample types, ie, PL LE2, PL HE2, FF LE2, and FF HE2 were respectively set for up- and down-regulated proteins. The paired comparisons made were PL HE2 and PL LE2, FF HE2 and FF LE2, PL HE2 and FF HE2, and PL LE2 and FF LE2. Functional analysis was performed for all identified proteins and for up- and down-regulated proteins.

\subsection{Bioinformatic analysis of identified proteins}

The PANTHER (Protein Analysis Through Evolutionary Relationships) classification system [14] was used to categorize the up- and down-regulated proteins based on their molecular function (MF), biological process (BP), and cellular component (CC)/localization. Pathway analysis was per-

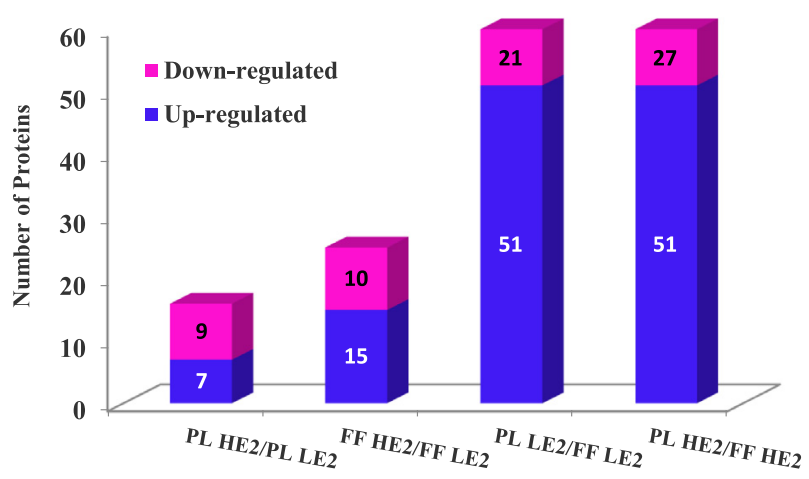

Fig. 1. The number of up- and down-regulated proteins (y-axis) after comparisons between any 2 samples (x-axis). The number of proteins in each category is shown on the bar.

formed using the Database for Annotation, Visualization and Integrated Discovery (DAVID) [15]. Pathway plot was derived using Kyoto Encyclopedia of Genes and Genomes (KEGG) [16].

\section{Results}

\subsection{General information on ITRAQ analysis}

A total of 231 proteins matched to 793 unique peptides were identified with high confidence (FDR of $5 \%$ or less) and were subsequently included in further analysis. From the 231 proteins, 221 (91.8\%) were commonly identified and quantified in both PL and FF, 12 were uniquely in PL, and 7 uniquely in FF.. Approximately 61\% (140/231) of proteins were identified by one unique peptide and $~ 39 \%$ by 2 unique peptides up to 47 unique peptides. About one third of proteins identified by one unique peptide were identified at $99 \%$ confidence. Analysis of the distribution of the sequence coverage of the detected peptides of the proteins found $53 \%$ (123/231) of identified proteins had greater than $5 \%$ coverage. The molecular mass of the identified proteins ranged from 10.3 to $3811.5 \mathrm{kDa}(110.4 \pm 266.6$ $\mathrm{kDa}$ ) with majority of the proteins $(\sim 60 \%)$ between 20 to $80 \mathrm{kDa}$. Protein pI values ranged from 4.41 to 11.05 . Several of the proteins identified herein have been previously reported as components of bovine PL and/or FF [3,17]. A total of 103 proteins significantly changed abundance as defined by fold change. The extents of fold change are shown Supplement Table 1.

\subsection{Comparative analysis of protein expression in plasma and follicular fluid}

Paired comparisons were made to determine differences in protein expression between any pair from the 4 samples: PL HE2, PL LE2, FF HE2, and FF LE2. Fig. 1 depicts the different paired comparisons and the number of up- and down-regulated proteins obtained in each analysis. Up- and down-regulated proteins were determined using a ratio fold-change of $>2.0$ or $<0.5$ between any 2 of the 4 sample types. Comparison between same fluid type (ie, PL HE2 and PL LE2 or FF HE2 and FF LE2) revealed 9 
A FF HE2/FF LE2
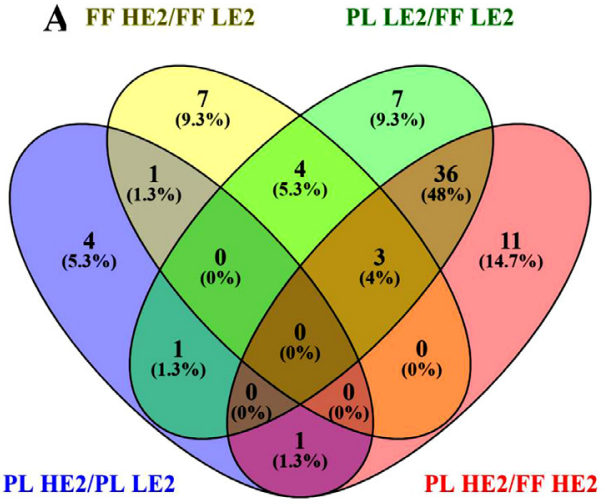

B FF HE2/FF LE2

PL LE2/FF LE2

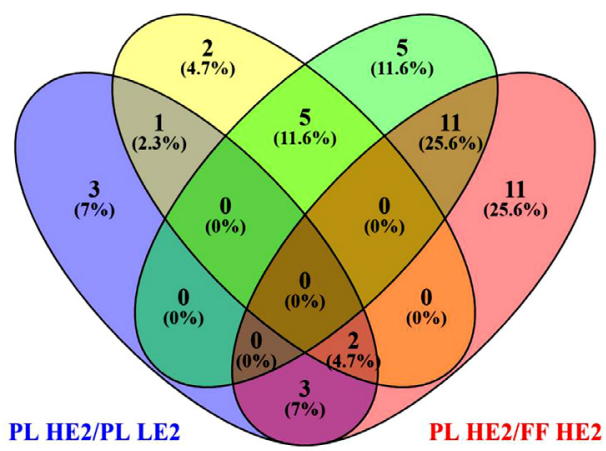

Fig. 2. Overlap of number of up-regulated (A) and down-regulated (B) proteins in PL and FF after paired analyses.

down-regulated and 7 up-regulated proteins in PL HE2 compared to PL LE2 and 10 down-regulated and 15 upregulated proteins in FF HE2 compared to FF LE2. Comparison between PL and FF showed more proteins up-regulated in PL compared to FF. Each PL and FF pair, (ie, PL LE2 and FF LE2; PL

HE2 and FF HE2) revealed 51 up-regulated proteins in PL. Twenty-one proteins were down-regulated in PL LE2 compared to FF LE2 whereas 27 proteins were downregulated in the PL HE2 compared to the FF HE2. Thirtynine up-regulated proteins and 11 down-regulated proteins were commonly identified from both PL and FF paired analyses. Overlaps of numbers of proteins from the different paired comparisons are depicted in Fig. 2.

The iTRAQ ratio value of a protein is indicative of the extent of up or down regulation of the protein in a sample. Comparison of FF HE2 to FF LE2 identified keratin type II cytoskeletal 7 (KRT7), serum albumin (ALB), and cytokine receptor like factor 3 (CRLF3) as the top 3 upregulated proteins and hemoglobin subunit alpha (HBA), hemoglobin subunit beta (HBB), and ubiquitin protein ligase E3 component n-recognin 4 (UBR4) as the top 3 downregulated proteins in the FF HE2. Suppressor of G2 allele of SKP1 homolog (SUGT1), C8G protein (C8G), and serglycin (SRGN) were the top 3 up-regulated proteins and DDB1 and CUL4 associated factor 5 (DCAF5), transmembrane protein 186 (TMEM186), and haptoglobin (HP) the top 3 down-regulated proteins in PL HE2 compared to PL LE2.

\subsection{Functions of identified proteins}

To determine the functions of all proteins showing expression changes, the up- and down-regulated proteins derived from all paired analyses were compiled (103 in total) and functional analysis performed using PANTHER classification system. The up- and down-regulated proteins were categorized into molecular function (MF), biological process (BP), and cellular component (CC; Fig. 3). The majority of the MF proteins were binding (52\%) and catalytic activity (40.0\%). The BP proteins were categorized into cellular component cellular process (33.3\%), metabolic process $(20.5 \%)$, organization or biogenesis $(6.8 \%)$, localization
(6.8\%), biological regulation (6.8\%), developmental process (6.8\%), multicellular organismal process $(6.0 \%)$, response to stimulus (5.1\%), biological adhesion (4.3\%), immune system process (2.6\%), and locomotion (0.9\%). Analysis of the CC proteins revealed the majority of the up and downregulated proteins were localized in the cell (31.8\%), the extracellular region (22.7\%) and organelle (21.2\%).

\subsection{Enriched pathways}

Database for Annotation, Visualization and Integrated Discovery (DAVID) was used to determine the pathways associated with the up- and down-regulated proteins in PL and FF. The databases within the DAVID platform searched were KEGG and Reactome [18] databases. Statistical enriched pathway, $P<0.05$, is based on Modified Fisher Exact (EASE Score). Results from KEGG showed the complement and coagulation cascades were enriched $\left(P=3.5 \times 10^{-14}\right.$; Fig. 4). The search in Reactome supported these enriched pathways by identifying platelet degranulation $\left(P=8.2 \times 10^{-9}\right)$, intrinsic pathway of fibrin clot formation $\left(P=1.4 \times 10^{-5}\right)$, common pathway of fibrin clot formation $\left(P=2.4 \times 10^{-4}\right)$, and scavenging of heme from plasma $\left(P=6.0 \times 10^{-3}\right)$ as the main pathways.

\section{Discussion}

Results of the present study support the hypothesis that increased circulating concentrations of E2 in bovine FF from dominant follicles is associated with greater abundance of proteins involved in final stages of folliculogenesis and ovulation. When evaluating reproductive success among cows, expression of estrus or elevated preovulatory concentrations of E2 has been reported as a potential biomarker of fertility. Estradiol is critical to the development and maturation of ovarian follicles [5,7]. Concentration of E2 in PL and/or FF has been positively correlated to increased oocyte quality, fertilization and subsequent embryo quality [19], increased follicle size, [8] and improved pregnancy success [20]. Considering the vital role of proteins in cell function and regulation, this study examined the associations between E2 and protein abundance in FF and PL. Both fluids were evaluated because of the significant similarities between PL and FF proteins that results 
(A) Molecular Function

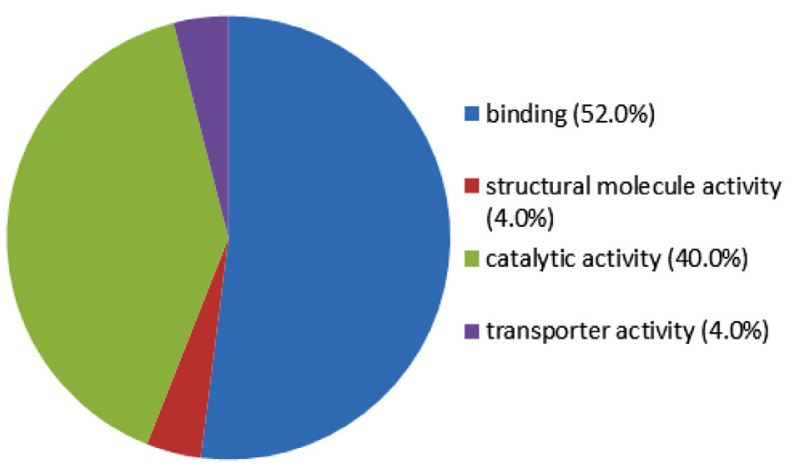

\section{(B) Cellular Component}

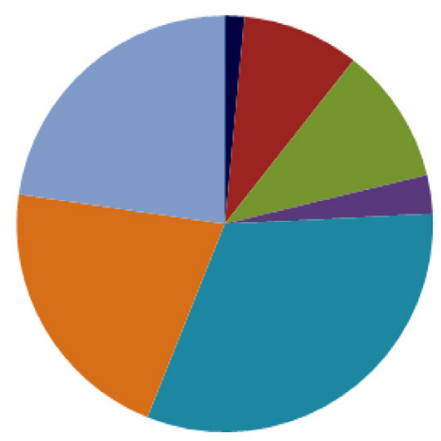

- synapse (1.5\%)

membrane (9.1\%)

- macromolecular complex (10.6\%)

n extracellular matrix (3.0\%)

n cell part (31.8\%)

च organelle (21.2\%)

n extracellular region (22.7\%)

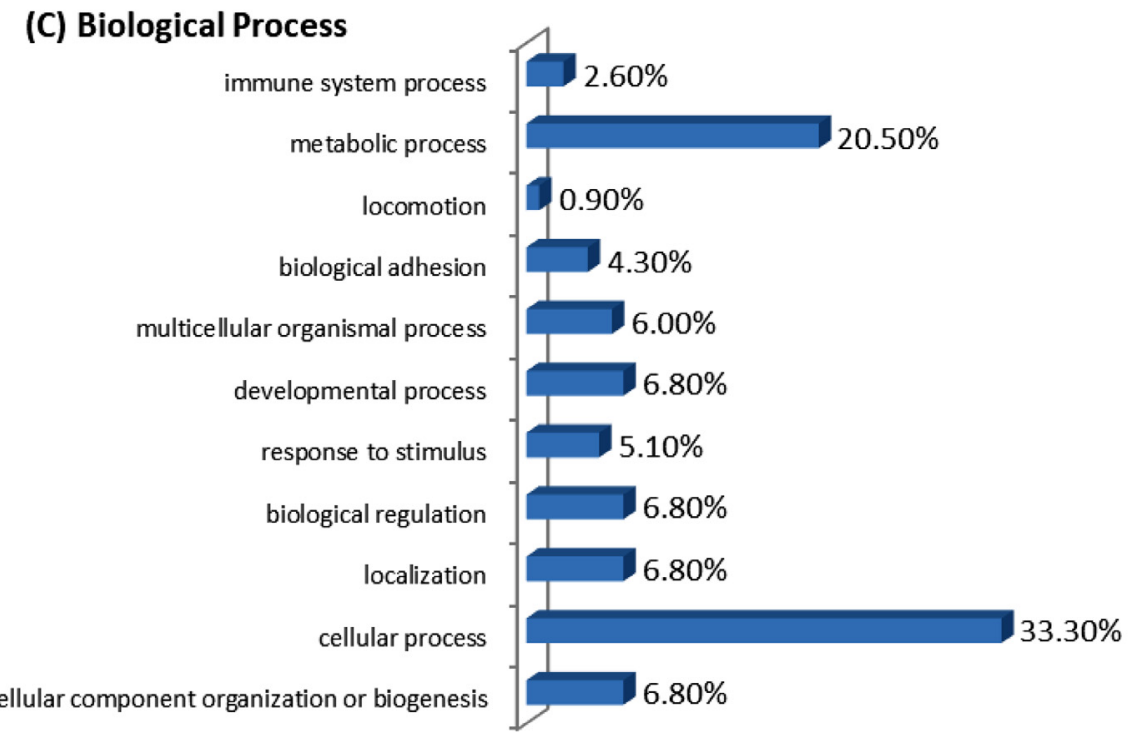

Fig. 3. PANTHER analysis of up- and down-regulated proteins identified in bovine plasma (PL) and follicular fluid (FF) containing low and high preovulatory E2. The up- and down-regulated proteins were compiled from PL HE2/PL LE2, FF HE2/FF LE2, PL LE2/FF LE2, and PL HE2/FF HE2 analyses. Proteins were classified according to (A) molecular function, (B) cellular localization, and (C) biological processes.

from the number of PL proteins capable of crossing the blood-follicular barrier during folliculogenesis [21,22].

A total of 103 proteins significantly changed abundance as defined by fold change with HE2 or LE2. The number and degree of fold change of proteins from the comparison between HE2 and LE2 in FF was greater than the corresponding PL comparison. This suggests preovulatory circulating concentration of E2 has a greater impact on FF proteome than on PL proteome. This is not surprising as E2 is produced by the GCs of ovarian follicles $[6,23]$ and FF is the immediate environment of the developing follicle and oocyte. The only predominant protein in PL HE2 that was also predominant in the FF HE2 when compared to the respective LE2 samples was KRT7 a member of the keratin gene family. The function of KRT7 is reported to be building structure integrity within complexes. Keratin genes are usually synthesized in pairs consisting of one type I and one type II as both are necessary to for an intermediate filament $[24,25]$. The presented data supports KRT7 involve- ment in developing follicles and possibly eliciting similar structural functions modulated by E2 in FF.

Because of the known impacts of E2 on pregnancy success, it is important to evaluate the results of this study in 2 different ways. The first is to determine if there are proteins that could be impacting the production of E2 by the dominant follicle. The second is to determine the impact that E2 is having on preparing the female for pregnancy success.

In evaluating proteins that could be impacting the production of E2 by the dominant follicle, PANTHER analysis revealed the up- and down-regulated proteins had multifunctional roles, but cellular process and metabolic process were the predominant functions. Developing ovarian follicles undergo a series of coordinated cellular processes that induce morphological and functional changes within the follicle, leading to cell differentiation and oocyte development [26]. Further analysis in PANTHER showed the proteins under cellular function were involved in cell 


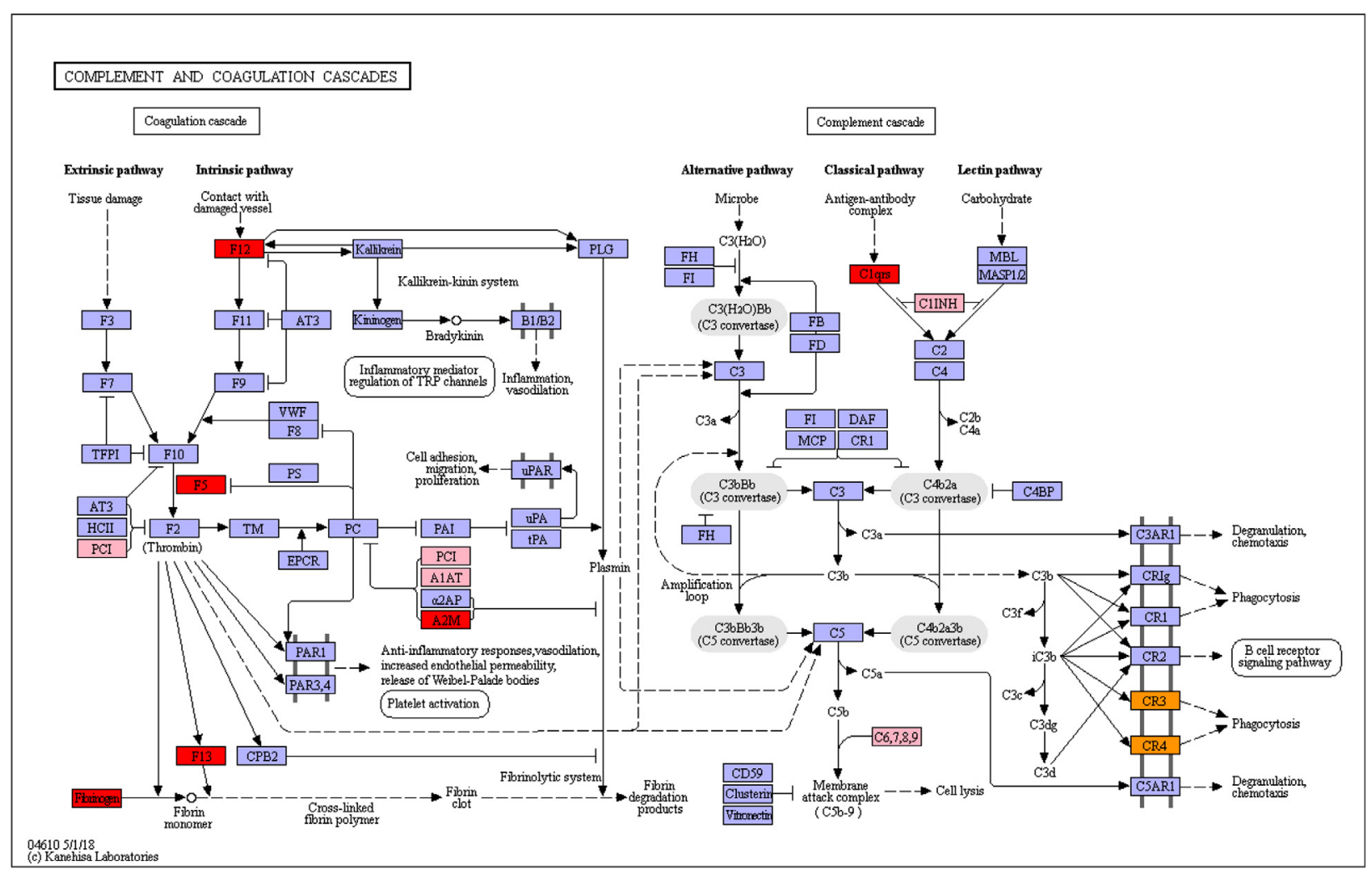

Fig. 4. Up-regulated (red) and down-regulated (pink) proteins involved in the complement and coagulation cascades identified in this study. Up- and downregulated in plasma (PL) compared to follicular fluid (FF): Alpha-2-macroglobulin (A2M), coagulation factor V (F5), coagulation factor XIII A chain (F13), complement C1s (C1S), complement C6 (C6), alpha-1-antiproteinase (A1AT or SERPINA1), plasma serine protease inhibitor (PCI or SERPINA5), factor XIIa inhibitor precursor (C1INH or SERPING1), complement C8 gamma chain (C8G; this was also up-regulated in PL HE2 compared to PL LE2), and fibrinogen (fibrinogen alpha chain (FGA), fibrinogen beta chain (FGB), and fibrinogen gamma chain (FGG)). Fibrinogen is a ligand of complement receptor types 3 and 4 (CR3 and CR4; orange). Up-regulated in FF HE2 compared to FF LE2: coagulation factor XII (F12). (For interpretation of the references to color in this figure legend, the reader is referred to the Web version of this article.)

communication (52.4\%), cellular component movement (23.8\%), cell growth $(4.8 \%)$, cell cycle (14.3\%), and chromosome segregation (4.8\%). Coordinated communications between the granulosa, cumulus, thecal cells, and the oocytes is critical for successful folliculogenesis and the development of oocytes capable for ovulation and fertilization [27]. Of these communication between the oocyte and GCs is considered the most significant for growth regulation and maturation of the oocyte and follicular luteinization. The proteins linked to cell communication identified in this study included inhibin alpha chain (INHA), fibronectin 1 transcript variant (FN1), fibrinogen gamma chain (FGG), fibrinogen beta chain (FGB), lumican (LUM), synaptotagmin-12 (SYT12), regulating synaptic membrane exocytosis 2 (RIMS2) and KRAS proto-oncogene, GTPase (KRAS). These proteins play vital roles in follicle growth and maturation.

Folliculogenesis is highly regulated by gonadotropins and sex hormones. The secretions of these hormones are in turn regulated by a number of proteins. Inhibin alpha is one such protein involved in the regulation of FSH secretion. Specifically, INHA selectively inhibits FSH secretion from the pituitary in a negative-feedback mechanism [28].
The decline in FSH results in circulating concentrations that can only be utilized by the largest follicle, thereby enhancing its growth to become the DF. The inability of smaller follicles to utilize the low circulating concentrations of FSH inhibits their growth $[29,30]$. Inhibin alpha was highly down-regulated in PL compared to FF with lower abundance in the high E2 pair (PL HE2/FF HE2; iTRAQ ratio 0.062) than the low E2 pair (PL LE2/FF LE2; iTRAQ ratio 0.079). The elevated INHA concentration in FF from high E2 is consistent with the vital roles of INHA and E2 in the decline of FSH observed during follicular deviation $[29,30]$. Apart from its role in regulating FSH secretion, INHA is also a critical regulator of different cellular processes including differentiation, cell migration, proliferation, and apoptosis [31].

The proteins FN1, FGB, FGG, and apolipoprotein R were classified under biological adhesion by PANTHER. Cell adhesion leads to alterations in cell shape and motility that are required for different cellular functions during folliculogenesis and the development of a competent oocyte $[32,33]$. Fibrinogen and FN1 have been reported to increase proliferation in several cell types. Specifically, FN1 has been reported to stimulate proliferation of ovarian GCs 
[34]. Successful ovulation and capture of the oocyte by the oviduct and subsequent transport through the oviduct necessitates formation and expansion of the cumulus celloocyte (COC) matrix [35]. Stabilization and expansion of the COC matrix involves binding of several proteins including FN1, versican core protein (VCAN), and laminin [36]. Furthermore, successful folliculogenesis requires adequate regulation of cellular apoptosis, and engulfment and cell motility 1 (ELMO1) has been reported to promote cellular apoptosis [37]. The down-regulation of ELMO1 in FF HE2 compared to FF LE2 supports the idea of decreased apoptosis in preovulatory follicles that are capable of producing elevated concentrations of estradiol. The suppression of ELMO1 in the presence of E2 at the preovulatory stage seems more localized in FF since it was more predominant in PL HE2 when compared to PL LE2.

In the opposite direction vitamin D-binding protein (GC) was down-regulated in the FF of HE2 animals compared to the FF in LE2 animals. Folliculogenesis involves proteins that transport and/or maintain substances including cells, cell components, metabolites and proteins in specific locations of action. Proteins involved in this process were categorized under localization. Such proteins included GC. GC is the main protein involved in the transport of 25-hydroxyvitamin D (25(OH)D), the precursor of the active form of vitamin $\mathrm{D}$ and the recognized optimal indicator of vitamin D status. Vitamin D level is therefore majorly contributed by GC level $[38,39]$. Based on the free hormone hypothesis that protein-bound hormones are not biologically available and that unbound hormones are biologically active, down-regulation of GC as found in this study can indicate more bioavailable 25(OH)D [38]. Apart from its well-known role in bone morphology, vitamin D is increasing being viewed as vital for regulation of reproduction physiology. Our data asserts a regulation of vitamin D by E2.

The second way to examine these data is to determine the impact that estradiol is having on preparing the female for pregnancy. The immune system in the reproductive tract plays a critical role in simultaneously providing a protective microenvironment to support successful reproduction processes and conferring protection against potential pathogens. The presence of immune system mediators during periovulatory follicle differentiation, ovulation and subsequent formation of the corpus luteum suggests active involvement of the immune system in these processes [40]. In fact, folliculogenesis and ovulation are viewed as a hormone-induced inflammatory processes [41]. Sex hormones, E2 and progesterone, significantly regulate the reproductive immune system cells, tissues and molecules [42]. This is supported by the results of this study demonstrating changes of immune-related proteins in the presence of high and low E2. Haptoglobin and immunoglobulin lambda-like polypeptide 1 were down-regulated in both plasma and follicular fluid while SRGN was up-regulated in the plasma of HE2 animals compared to LE2 animals.

Pathway analysis revealed that the complement and coagulation cascades were the predominant pathways, consistent with previous studies on FF $[3,43]$. Stage of follicle development seems to regulate the proteins involved in coagulation pathway. Proteins involved in coagulation were found down-regulated in the predeviation, early deviation and preovulatory stages and up-regulated in later deviation to postdeviation stages [3]. Here, the coagulation and complement pathway involved 13 proteins showing different levels of expression changes, supporting a dependence on individual protein roles in the pathway. The predominance of the complement and coagulation cascades supports the view that the follicle development and ovulation are hemorrhagic and inflammatory induced events, and increased concentrations of estradiol are preparing the body for this event.

The complement cascade and coagulation cascade are closely related and each activates the other in a reciprocal way. For instance, activated platelets can activate the classical and alternative complement pathways. Thrombin, coagulation factors FIXa, FXa, FXIa, and plasmin can activate $\mathrm{C} 3$ and $\mathrm{C} 5$. F12a can activate C1qrs complex to activate the classical complement pathway. Conversely, mannanbinding lectin associated serine protease 2 (MASP-2) and the final stage complement complex C5b-9 are able to generate thrombin through direct cleavage of prothrombin. Thrombin is a vital coagulation component that converts fibrinogen to fibrin.

Coagulation factor 12 (F12) is the first component of the coagulation pathway and its activation triggers the intrinsic pathway of the coagulation system [44]. Coagulation factor 12 was up-regulated in FF HE2 compared to FF LE2, indicating a greater influence of E2 on F12 in FF. Five other proteins were down-regulated in PL compared to FF namely alpha-1 antitrypin (A1AT), plasma serine protease inhibitor $(\mathrm{PCI})$, factor XIIa inhibitor precursor (C1INH), complement C6 (C6), and complement C8 gamma chain (C8G). Alpha-1 antitrypin expression in FF HE2 was about double that in FF LE2 when compared to the corresponding PL samples. Alpha-1 antitrypin, C1INH and PCI are protease inhibitors belonging to the SERPIN superfamily. The SERPINs regulate a wide range of proteins including those involved in the coagulation, fibrinolysis, and complement pathways $[45,46]$. In conclusion, E2 concentrations associated with changes in abundance of several proteins in both PL and FF. The relative changes of several of the proteins are consistent with their function in follicle growth and maturation, and in preparing the reproductive tract for pregnancy success. Furthermore, the coagulation and complement cascades are enriched during bovine follicle development and support the view that folliculogenesis and ovulation are hemorrhagic events.

\section{Authors' contribution}

P.A. Afedi: Formal Analysis, Investigation, Writing Original Draft, Writing - Review \& Editing; E.L. Larimore: Conceptualization, Investigation, Writing - Review \& Editing; R.A. Cushman: Conceptualization, Investigation, Writing - Review \& Editing, Supervision; D. Raynie: Formal Analysis, Writing - Reviewing \& Editing, Supervision; G.A. Perry: Conceptualization, Methodology, Investigation, Resources, Writing - Review \& Editing, Supervision, Funding acquisition. 


\section{Supplementary materials}

Supplementary material associated with this article can be found, in the online version, at doi:10.1016/j.domaniend. 2021.106606.

\section{References}

[1] Schweigert FJ, Gericke B, Wolfram W, Kaisers U, Dudenhausen JW. Peptide and protein profiles in serum and follicular fluid of women undergoing ivf. Hum Reprod 2006;21:2960-8.

[2] Shalgi R, Kraicer P, Rimon A, Pinto M, Soferman N. Proteins of human follicular fluid: the blood-follicle barrier. Presented at the annual conference of the society for the study of fertility, reading, England, July 18-22, 1972. Fertil Steril 1973;24:429-34.

[3] Ferrazza RdA, Garcia HDM, Schmidt EMdS, Mihm Carmichael M, de Souza FF, Burchmore R, Sartori R, Eckersall PD, Ferreira JCP. Quantitative proteomic profiling of bovine follicular fluid during follicle development. Biol Reprod 2017;0:1-15.

[4] Spitzer D, Murach KF, Lottspeich F, Staudach A, Illmensee K. Different protein patterns derived from follicular fluid of mature and immature human follicles. Hum Reprod 1996;11:798-807.

[5] Drummond AE, Findlay JK. The role of estrogen in folliculogenesis. Mol Cell Endocrinol 1999;151:57-64.

[6] Bentov Y, Jurisicova A, Kenigsberg S, Casper RF. What maintains the high intra-follicular estradiol concentration in pre-ovulatory follicles? J Assisted Reprod Genet 2016;33:85-94.

[7] Emmen JMA, Couse JF, Elmore SA, Yates MM, Kissling GE, Korach KS. In vitro growth and ovulation of follicles from ovaries of estrogen receptor (er) $\alpha$ and er $\beta$ null mice indicate a role for er $\beta$ in follicular maturation. Endocrinology 2005;146:2817-26.

[8] Perry GA, Swanson OL, Larimore EL, Perry BL, Djira GD, Cushman RA. Relationship of follicle size and concentrations of estradiol among cows exhibiting or not exhibiting estrus during a fixed-time ai protocol. Domest Anim Endocrinol 2014;48:15-20.

[9] Larimore EL, Amundson OL, Bridges GA, McNeel AK, Cushman RA, Perry GA. Changes in ovarian function associated with circulating concentrations of estradiol before a gnrh-induced ovulation in beef cows. Domest Anim Endocrinol 2016;57:71-9.

[10] Aggarwal S, Yadav AK. Dissecting the itraq data analysis. In: Jung K, editor. Statistical analysis in proteomics. New York: Springer; 2016. p. 277-91.

[11] Perry GA, Perry BL. Effect of preovulatory concentrations of estradiol and initiation of standing estrus on uterine ph in beef cows. Domest Anim Endocrinol 2008;34:333-8.

[12] Jinks EM, Smith MF, Atkins JA, Pohler KG, Perry GA, MacNeil MD, Roberts AJ, Waterman RC, Alexander LJ, Geary TW. Preovulatory estradiol and the establishment and maintenance of pregnancy in suckled beef cows1. J Anim Sci 2013;91:1176-85.

[13] Afedi PA, Jing L, Perry GA, Raynie DE. Immunodepletion of multiple high-abundant proteins from bovine fluids. J Bioanal Methods Tech 2020;1:101-11.

[14] Mi H, Muruganujan A, Casagrande JT, Thomas PD. Large-scale gene function analysis with the panther classification system. Nat Protocols 2013:8:1551.

[15] Huang DW, Sherman BT, Lempicki RA. Systematic and integrative analysis of large gene lists using David bioinformatics resources. Nat Protocols 2008;4:44-57.

[16] Kanehisa M, Furumichi M, Tanabe M, Sato Y, Morishima K. Kegg: new perspectives on genomes, pathways, diseases and drugs. Nucleic Acids Res 2017;45:D353-61.

[17] Sun D, Zhang H, Guo D, Sun A, Wang H. Shotgun proteomic analysis of plasma from dairy cattle suffering from footrot: characterization of potential disease-associated factors. PloS One 2013;8:e55973.

[18] Fabregat A, Jupe S, Matthews L, Sidiropoulos K, Gillespie M, Garapati P, Haw R, Jassal B, Korninger F, May B, Milacic M, Roca CD, Rothfels K, Sevilla C, Shamovsky V, Shorser S, Varusai T, Viteri G, Weiser J, Wu G, Stein L, Hermjakob H, D'Eustachio P. The reactome pathway knowledgebase. Nucleic Acids Res 2018;46:D649-55.

[19] Sarhan D, El Mazny A, Taha T, Aziz A, Azmy O, Fakhry D, Torky H. Estradiol and luteinizing hormone concentrations in the follicular aspirate during ovum pickup as predictors of in vitro fertilization (ivf) outcome. Middle East Fertil Soc J 2017;22:27-32.

[20] Perry GA, Smith MF, Lucy MC, Green JA, Parks TE, MacNeil MD, Roberts AJ, Geary TW. Relationship between follicle size at insemination and pregnancy success. Proc Natl Acad Sci U S A 2005; 102:5268
[21] Siu MKY, Cheng CY. The blood-follicle barrier (bfb) in disease and in ovarian function. Adv Exp Med Biol 2012;763:186-92.

[22] Hess KA, Chen L, Larsen WJ. The ovarian blood follicle barrier is both charge- and size-selective in mice. Biol Reprod 1998;58:705-11.

[23] Hu J, Zhang Z, Shen W-J, Azhar S. Cellular cholesterol delivery, intracellular processing and utilization for biosynthesis of steroid hormones. Nutr Metab 2010;7 47-47.

[24] Eichner RBP, Sun TT. Classification of epidermal keratins according to their immunoreactivity, isoelectric point, and mode of expression. J Cell Biol 1984;98:1388-96.

[25] Sun TT, Eichner R, Schermer A, Cooper D, Nelson WG, Weiss RA. Classification, expression, and possible mechanisms of evolution of mammalian epithelial keratins: a unifying model. Cancer Cells 1984;1:169-76.

[26] \#xc1, ngel Palma GA, Arga \#xf1, araz ME, Barrera AD, Rodler D, Mutto A, Sinowatz F. Biology and biotechnology of follicle development. Sci World J 2012;2012:14.

[27] Russell DL, Robker RL. Molecular mechanisms of ovulation: co-ordination through the cumulus complex. Hum Reprod Update 2007;13:289-312.

[28] Luisi S, Florio P, Reis FM, Petraglia F. Inhibins in female and male reproductive physiology: role in gametogenesis, conception, implantation and early pregnancy. Hum Reprod Update 2005;11:123-35.

[29] Beg M, Meira C, Bergfelt D, Ginther O. Role of oestradiol in growth of follicles and follicle deviation in heifers. Reproduction 2003; 125:847-54.

[30] Ginther OJ, Bergfelt DR, Kulick LJ, Kot K. Selection of the dominant follicle in cattle: role of estradiol1. Biol Reprod 2000;63:383-9.

[31] Aleman-Muench GR, Soldevila G. When versatility matters: activins/inhibins as key regulators of immunity. Immunol Cell Biol 2012;90:137-48.

[32] Mora JM, Fenwick MA, Castle L, Baithun M, Ryder TA, Mobberley M, Carzaniga R, Franks S, Hardy K. Characterization and significance of adhesion and junction-related proteins in mouse ovarian follicles1. Biol Reprod 2012;86:153 151-114-153, 151-114.

[33] Woodruff TK, Shea LD. The role of the extracellular matrix in ovarian follicle development. Reprod Sci (Thousand Oaks, Calif) 2007;14:6-10.

[34] Asem EK, Carnegie JA, Tsang BK. Fibronectin production by chicken granulosa cells in vitro: effect of follicular development. Acta Endocrinol 1992;127:466-70.

[35] Huang Z, Wells D. The human oocyte and cumulus cells relationship: new insights from the cumulus cell transcriptome. MHR: Basic Sci Reprod Med 2010;16:715-25.

[36] Familiari G, Heyn R, Relucenti M, Nottola SA, Sathananthan AH. Ultrastructural dynamics of human reproduction, from ovulation to fertilization and early embryo development. In: International review of cytology, 249. Elsevier; 2006. p. 53-141.

[37] Elliott MR, Zheng S, Park D, Woodson RI, Reardon MA, Juncadella IJ, Kinchen JM, Zhang J, Lysiak JJ, Ravichandran KS. Unexpected requirement for elmo1 in apoptotic germ cell clearance in vivo. Nature 2010;467:333-7.

[38] Jassil NK, Sharma A, Bikle D, Wang X. Vitamin D binding protein and 25-hydroxyvitamin d levels: emerging clinical applications. Endocr Pract 2017;23:605-13.

[39] Yousefzadeh P, Shapses SA, Wang X. Vitamin D binding protein impact on 25-hydroxyvitamin d levels under different physiologic and pathologic conditions. Int J Endocrinol 2014;2014:6.

[40] Abdulrahman N, Fair T. Contribution of the immune system to follicle differenation, ovulation and early luteum formation. Anim Reprod 2019;16:440-8.

[41] Boots CE, Jungheim ES. Inflammation and human ovarian follicular dynamics. Semin Reprod Med 2015;33:270-5.

[42] Nguyen PV, Kafka JK, Ferreira VH, Roth K, Kaushic C. Innate and adaptive immune responses in male and female reproductive tracts in homeostasis and following HIV infection. Cell Mol Immunol 2014; 11:410-27.

[43] Shen X, Liu X, Zhu P, Zhang Y, Wang J, Wang Y, Wang W, Liu J, Li N, Liu F. Proteomic analysis of human follicular fluid associated with successful in vitro fertilization. Reprod Biol Endocrinol 2017;15:58.

[44] Kenawy HI, Boral I, Bevington A. Complement-coagulation cross-talk: a potential mediator of the physiological activation of complement by low pH. Front Immunol 2015;6:215.

[45] Gettins PGW, Olson ST. Inhibitory serpins. New insights into their folding, polymerization, regulation and clearance. Biochem J 2016;473:2273-93

[46] Law RHP, Zhang Q McGowan S, Buckle AM, Silverman GA, Wong W, Rosado CJ, Langendorf CG, Pike RN, Bird PI, Whisstock JC. An overview of the serpin superfamily. Genome Biol 2006;7 216216. 